\title{
Ganoderma tsugae in vivo modulates Th1/Th2 and macrophage responses in an allergic murine model
}

\author{
Jin-Yuarn Lin ${ }^{\mathrm{a}, *}$, Miaw-Ling Chen ${ }^{\mathrm{b}}$, Bi-Fong Lin ${ }^{\mathrm{b}, *}$ \\ a Department of Food Science and Biotechnology, College of Agriculture and Natural Resources, National Chung Hsing University, \\ 250 Kuokuang Road, Taichung 40227, Taiwan, ROC \\ ${ }^{\mathrm{b}}$ Department of Biochemical Science and Technology, College of Life Science, National Taiwan University, No. 1, Sec. 4, Roosevelt Road, \\ Taipei 10617, Taiwan, ROC
}

Received 14 October 2005; accepted 4 July 2006

\begin{abstract}
We have reported that Ganoderma tsugae supplementation alleviates bronchoalveolar inflammation in an airway sensitization and challenge model with female BALB/c mice. However, the effects of $G$. tsugae supplementation in vivo on serum antibody levels, splenocyte and peritoneal microphage immune responses have not yet been determined. In this study, serum antibody levels, cytokines and splenocyte chemical mediators and peritoneal macrophage cultures from ovalbumin (OVA)-sensitized and -challenged mice were examined after continuously consuming $G$. tsugae supplementation diets for 5 weeks. The results showed that OVA sensitization and challenge significantly $(P<0.05)$ decreased the spontaneous production of IL-2 (Th1) cytokine, but significantly $(P<0.05)$ increased spontaneous and OVA-stimulated IL-4 (Th2) production in splenocyte cultures from experimental mice. OVA administration significantly decreased both spontaneous and LPS/IFN- $\gamma$-stimulated IL-1 $\beta$ and IL-6 levels in peritoneal macrophage cultures from experimental mice. However, dietary supplementation with $G$. tsugae significantly increased spontaneous IL-2 level, but slightly decreased spontaneous IL-4 level in cultured splenocyte supernatants in the experimental groups. G. tsugae supplementation enhanced pro-inflammatory cytokines IL-1 $\beta$ and IL-6 production in cultured peritoneal macrophages. However, the nitric oxide level from cultured peritoneal macrophages and serum OVA-specific IgE and $\mathrm{IgG}_{2 \mathrm{a}}$ antibody levels was not significantly affected. These results suggest that OVA sensitization and challenge induced a Th2-skewed splenocyte response and decreased peritoneal macrophage cytokine secretion. G. tsugae supplementation in vivo modulated the Th1/Th2 balance and enhanced macrophage immune responses. However, the supplementation diet could not fully reverse the Th2-skewed responses to level of Th1-skewed responses.
\end{abstract}

(C) 2006 Elsevier Ltd. All rights reserved.

Keywords: Ganoderma tsugae; Splenocytes; T-helper type 1 (Th1) cytokine; Th2 cytokine; Peritoneal macrophages; Allergic murine model

\section{Introduction}

Th1 cells are mainly involved in cell-mediated immune responses and commonly express interferon- $\gamma$ (IFN- $\gamma$ ) and interleukin-2 (IL-2). Th2 cells are involved in humoral immune responses and commonly produce GM-CSF, IL-4, IL-5, IL-6, IL-9, IL-10, IL-13, and macrophage-derived

\footnotetext{
${ }^{*}$ Corresponding authors. Tel.: +886 42285 1857; fax: +886 422851857 (J.-Y. Lin); tel.: +886 23366 4451; fax: +886 223621301 (B.-F. Lin). E-mail addresses: jinlin@nchu.edu.tw(J.-Y. Lin), bifong@ntu.edu.tw (B.-F. Lin)
}

chemokines (Ogawara et al., 2005; Romagnani, 2000). Th1 cytokines, such as IFN- $\gamma$ and IL-12, inhibit eosinophil infiltration, $\mathrm{IgE}$ and $\mathrm{IgG}_{1}$ production, but strengthen $\mathrm{IgG}_{2 \mathrm{a}}$ production in vivo (Morokata et al., 1999). Thus, IgE and $\mathrm{IgG}_{1}$ antibodies may be roughly defined as Th2-type immunoglobulins, while $\operatorname{IgG}_{2 \mathrm{a}}$ may be roughly defined as a Th1-type immunoglobulin. The interplay in the cytokine network and humoral immune responses regulates the immune system. However, an imbalance in Th1 and Th2 cell functions results in various disorders. A Th2-skewed pattern in vivo, such as the allergic disorder, might play a triggering role in the activation and/or recruitment of $\operatorname{IgE}$ 
antibody-producing B cells, mast cells and eosinophils, i.e. the cellular triad involved in allergic inflammation (Maggi, 1998). In vivo immunomodulating the balance between Th1 and Th2 cells, and humoral immune responses might reduce the incidence of allergic diseases. Macrophages are important in the innate and adaptive immunity as professional antigen-presenting cells and effector cells in the humoral and cell-mediated immunity. Macrophages might take part in the allergic diseases. However, the interaction among macrophages, Th1/Th2, and humoral immune responses in allergic diseases is seldom discussed.

A great deal of research has been done on exploring a possible therapeutic application for traditional medicines (Li et al., 2000; Kato et al., 2003; Ko et al., 2004) or health foods (Cross et al., 2001) in allergic disease. It has been found that treatment with fms-like tyrosine kinase 3 (Flt3) ligand plasmid reverses allergic airway inflammation accompanied with increasing serum anti-OVA IGg2a and decreasing IL-4 and IgE levels in ovalbumin-sensitized and -challenged mice (Edwan et al., 2005). Ganoderma are traditionally introduced into Chinese medicine and widely used as medicinal mushrooms in Asian countries. Ganoderma lucidum (Reishi) is well known for its immuno-modulatory and anti-tumor activities (Chen et al., 2004; Chien et al., 2004). The activities of G. lucidum are produced by its polysaccharide components. Recently, the characteristics of active polysaccharides from G. lucidum have been unraveled (Wang et al., 2002). Ganoderma tsugae, the most widely cultivated species of medicinal mushrooms in Taiwan, has been reported to be effective in the treatment of many diseases, such as tumors (Peng et al., 2003; Peng et al., 2005), wound healing (Su et al., 1999), liver fibrosis (Wu et al., 2004), and autoimmune diseases (Lai et al., 2001). It is reported that water-soluble and alcohol-soluble extracts of $G$. tsugae mycelia enhance splenic natural killer cell activities and interferon serum levels in mice (Won et al., 1992). Anti-tumor active polysaccharides from the fruiting bodies of $G$. tsugae have also been characterized (Wang et al., 1993). These researches provide the possibility of alleviating allergic diseases using traditional medicines or health foods via immuno-modulation of the Th1/Th2 balance or humoral immune responses in vivo.

In our previous work, $G$. tsugae supplementation alleviated bronchoalveolar inflammation via decreasing inflammatory cell infiltration and the secretion of inflammatory mediators into the local lung and airway tissues in an established airway sensitization and challenge model with female BALB/c mice (Lin et al., 2006). However, the immuno-regulation of $G$. tsugae on humoral immunity, $\mathrm{T}$-cell and macrophages in the allergic immune response has not yet been determined. In this study, G. tsugae supplementation diets, YK01 and YK07, prepared from the fruiting bodies and mycelia of $G$. tsugae were conducted in vivo to investigate the immuno-modulation of humoral, Th1/Th2, and peritoneal macrophage immune responses using an ovalbumin (OVA)-sensitized and -challenged allergic inflammation murine model.

\section{Materials and methods}

\subsection{Materials and sample preparations}

G. tsugae samples were obtained from Yung-Kien Industry Corp, Double Crane Group, Taiwan, ROC. Two products, G. tsuga YK01 and YK07, were used to test the immuno-modulatory effects on humoral responses, Th1/Th2 balance, and peritoneal macrophages in an airway sensitization murine model. Both YK01 and YK07 products were prepared from the same species of $G$. tsugae. The YK01 was prepared from baby $G$. tsugae, harvested at 2-3 weeks after fruiting, whereas the YK07 was prepared from mature $G$. tsugae, harvested 1-2 months after fruiting. The original G. tsugae source was selected from a wild type growing in Puli, Nantou, Taiwan and then named G. tsugae YK-01. After suitable cultivation, mycelia and fruit bodies from $G$. tsugae were harvested and extracted twice using hot water, respectively. The hot-water-extracts were spray-dried to obtain dry powder. According to the preliminary data, the dry powders extracted from the mycelia and fruit bodies were mixed at a fixed ratio. The G. tsugae products were finally encapsulated and preserved at room temperature. Both $G$. tsuga YK01 and YK07 contained approximate components and consist of $0.28 \%$ proteins, $0 \%$ lipids, $55.56 \%$ carbohydrates (including $12.5 \%$ polysaccharides), $1.67 \%$ sodium, and $12 \%$ triterpenes.

\subsection{Experimental animals and feeds}

Inbred female BALB/cByJNarl mice ( 6 weeks old) were purchased from the Laboratory Animal Center, College of Medicine, National Taiwan University and maintained in the Department of Biochemical Science and Technology, College of Life Science, National Taiwan University. The animal room was kept on a 12-h light and 12-h dark cycle. Constant temperature $\left(25 \pm 2{ }^{\circ} \mathrm{C}\right)$ and humidity were maintained. The mice were housed and kept on a chow diet (laboratory standard diet) to acclimatize for 2 weeks before feeding the experimental diet. After this equilibrium period, the mice were divided into six groups $(n=14)$ including nonsensitized control (SC), dietary control (DC), and G. tsugae supplementation groups, YK01-L, YK01-H, YK07-L, YK07-H. Each group was fed with one of the specified experimental diets for five consecutive weeks ad libitum. Neither the SC nor the DC groups received G. tsugae. A series of preliminary experiments were conducted to determine the effective dosage and safety evaluation for G. tsugae products. According to the preliminary data (Lin et al., 2006), the G. tsugae diet formulas were used in this study. The specified diets consisted of AIN 76 semi-purified diets supplemented with G. tsuga YK01 and YK07, respectively. Non-sensitized control (SC), dietary control (DC) groups were fed with AIN 76 feed. The ingredients and experimental feed compositions are described as in Lin et al. (2006). The YK01-L (low dose supplementation with YK01) and YH01-H (high dose supplementation with YK01) feed diets were prepared by through mixing 2.0 and $4.0 \mathrm{~g}$ G. tsugae YK01 with $1000 \mathrm{~g}$ AIN76 feed, respectively. The YK07-L (low dose supplementation with YK07) and YK07-H (high dose supplementation with YK07) feed diets were prepared by through mixing 3.3 and $6.6 \mathrm{~g} \mathrm{G}$. tsugae YK01 with $1000 \mathrm{~g}$ AIN76 feed, respectively. Mice food intake and body weight were measured every 3 days during the study period. There were no differences in food intake, feed efficiency and body weight gain between the six groups.

\subsection{OVA-sensitized and-challenged allergic inflammation murine model}

To test the effects of G. tsugae on allergic disorders, the mice ( 9 weeks old) were sensitized and challenged with ovalbumin (OVA) to establish an OVA-sensitized and -challenged allergic inflammation murine model. The mouse model was manipulated as described by Nagai et al. (2004) and slightly modified to enhance the allergic inflammation induction. All groups except SC were sensitized and challenged with OVA. In brief, mice were sensitized using an intraperitonal injection (i.p.) of $0.5 \mathrm{ml}$ alumprecipitated antigen containing $8 \mu \mathrm{g}$ of ovalbumin (OVA, albumin chicken 
egg grade III, Sigma A-5378, MO, USA) and $2 \mathrm{mg} \mathrm{Al}(\mathrm{OH})_{3}$ to induce primary immunity after supplementation of $G$. tsugae diets for 1 week. Two booster injections of this alum-OVA mixture were given 7 and 14 days later, respectively. Non-sensitized control mice received alum only. One week later, the mice were then challenged twice at 3 day intervals using aerosolized OVA at a concentration of $50 \mathrm{mg}$ OVA per milliliter phosphate-buffered saline (PBS; $137 \mathrm{mM} \mathrm{NaCl}, 2.7 \mathrm{mM} \mathrm{KCl}, 8.1 \mathrm{mM}$ $\mathrm{Na}_{2} \mathrm{HPO}_{4}, 1.5 \mathrm{mM} \mathrm{KH} \mathrm{PO}_{4}, \mathrm{pH}$ 7.2-7.4, $0.2 \mu \mathrm{m}$ filtered) for $30 \mathrm{~min}$. The aerosolized OVA were created using an ultrasonic nebulizer (Ultra-Neb99, Devilbiss). Non-sensitized control mice received PBS only. Two days later, the animals were anesthetized with diethyl ether, exsanguinated using retro-orbital venous plexus puncture and immediately euthanized using $\mathrm{CO}_{2}$ inhalation. The spleen and peritoneal cells (mostly macrophages) were collected, prepared and then cultured, respectively. Mouse serum was collected weekly to determine the changes in OVA-specific IgE, and $\operatorname{IgG}_{2 \mathrm{a}}$ antibodies during the experimental period.

\subsection{Collection of peritoneal cells and splenocytes}

Briefly, the mice were anesthetized with diethyl ether, bled using retroorbital venous plexus puncture to collect blood and immediately euthanized using $\mathrm{CO}_{2}$ inhalation. Peritoneal cells were prepared by lavaging the peritoneal cavity with two aliquots of $5 \mathrm{ml}$ sterile Hank's balanced salts solution (HBSS) for a total of $10 \mathrm{ml}$ through the peritoneum. The peritoneal adherent cells (mostly macrophages) from each animal were adjusted to $3 \times 10^{6}$ cells $/ \mathrm{ml}$ in TCM medium. The splenocytes were prepared by aseptically removing spleens from BALB/c mice. The spleen was ground with the flat bottom of a syringe piston to homogenize the splenocytes. Splenocytes were isolated from each animal and adjusted to $1 \times 10^{7}$ cells $/ \mathrm{ml}$ in TCM medium. Total leukocytes collected from the peritoneal cavity and spleen of each mouse were counted with a hemocytometer using the Trypan blue dye exclusion method. Peritoneal adherent cells (mostly macrophages) and splenocytes $(0.50 \mathrm{ml} /$ well) without or with mitogens $(0.50 \mathrm{ml} /$ well), such as lipopolysaccharide (LPS, $10 \mu \mathrm{g} / \mathrm{ml}$ ) and interferon- $\gamma$ (IFN- $\gamma, 50$ units $/ \mathrm{ml}$ ) or ovalbumin (OVA, $25 \mu \mathrm{g} / \mathrm{ml}$ ), respectively, were plated in 24-well plates. The plates were incubated at $37{ }^{\circ} \mathrm{C}$ in a humidified incubator with $5 \% \mathrm{CO}_{2}$ and $95 \%$ air for $48 \mathrm{~h}$. The supernatants in cell cultures were collected and stored at $-70{ }^{\circ} \mathrm{C}$ for cytokine and inflammatory mediator assays.

\subsection{Measurement of cytokine and inflammatory mediator levels secreted by peritoneal cell and splenocyte cultures by an enzyme-linked immunosorbent assay (ELISA)}

\subsubsection{IL-1 $\beta, I L-2, I L-4$, and $I L-6$ levels in peritoneal cell or splenocyte cultures}

Cytokine (IL-1 $\beta$, IL-2, IL-4, IL-6) levels were determined using sandwich ELISA kits, respectively. The IL-2 level was quantified using mouse IL-2 ELISA set (BD Biosciences Pharmingen, San Diego, CA, USA). The sensitivity for IL-2 was $<3.1 \mathrm{pg} / \mathrm{ml}$. The IL- $1 \beta$, IL-4, and IL-6 concentrations were assayed using mouse DuoSet ELISA Development system (R\&D systems, Inc., Mineapolis, USA). The sensitivity of these cytokine assays was about $15.6 \mathrm{pg} / \mathrm{ml}$. The IL-1 $\beta$, IL-2, IL-4, and IL-6 concentrations were assayed according to the cytokine ELISA protocol in the manufacturers' instructions. Finally, the plates were measured obtaining absorbance at $450 \mathrm{~nm}$ on a plate reader (ELISA reader, ASYS Hitech GmbH, Austria). The IL-1 $\beta$, IL-2, IL-4, and IL-6 levels in the cell cultures were determined using a seven point standard, respectively.

\subsubsection{Nitric oxide (NO) levels in peritoneal cell cultures}

Aliquots of $80 \mu \mathrm{l}$ of samples and standards $(0-100 \mu \mathrm{M}$ sodium nitrite (Sigma S-2252) dissolved in double distilled water) were pipeted into the 96 microplate wells (Nunc), respectively. Aliquots of $160 \mu \mathrm{l}$ Griess reagent were then added into each well to develop the color. The Griess reagent was freshly prepared from Reagents A and B at a ratio of 1:1, (Reagent A: 2\% $(\mathrm{w} / \mathrm{v})$ sulfanilamide (Sigma S-9251) dissolved in 2.5\% (v/v) phosphoric acid; Reagent B: $0.2 \%(\mathrm{w} / \mathrm{v}) \mathrm{N}$-1-naphthylethylene diamide dihydrochloride
(Sigma N-9125) dissolved in 2.5\% (v/v) phosphoric acid). After incubation for $10 \mathrm{~min}$, the plate was read on a plate reader (ELISA reader, ASYS Hitech $\mathrm{GmbH}$, Austria) at $540 \mathrm{~nm}$. The NO concentration for each unknown sample was determined using the standard curve.

\section{6. $O V A$-specific $\operatorname{IgE}$, and $\operatorname{Ig} G_{2 a}$ assay}

A sandwich ELISA protocol was used to determine the OVA-specific $\mathrm{IgE}$ and $\mathrm{IgG}_{2 \mathrm{a}}$ antibody levels in the serum. Aliquots of $200 \mu \mathrm{l} /$ well OVA $\left(10 \mu \mathrm{g} / \mathrm{ml}\right.$ dissolved in $\left.0.1 \mathrm{M} \mathrm{NaHCO}_{3}, \mathrm{pH} 8.2\right)$ were pipeted into the 96 wells EIA/RIA microplate (Nunc), respectively. Plates were incubated overnight at $4{ }^{\circ} \mathrm{C}$. Then, the plates were carefully washed with PBS three times. Aliquots of $200 \mu \mathrm{l} /$ well blocking solution ( $1 \%$ bovine serum albumin (BSA, Sigma) in PBS buffer) were pipeted into the 96 microplate wells to block the free sites on the wells, respectively. After incubation for $2 \mathrm{~h}$ at room temperature, the plates were carefully washed with PBST buffer $(0.05 \%$ Tween 20 (Sigma) in PBS) three times. Serum samples were diluted 1:10 (for $\operatorname{IgE}$ detection) and 1:150 (for $\operatorname{IgG}_{2 \mathrm{a}}$ detection) in PBST buffer. Aliquots of $100 \mu \mathrm{l} /$ well diluted serum samples were pipeted into the 96 microplate wells, respectively and incubated overnight at $4{ }^{\circ} \mathrm{C}(\mathrm{IgE}$ detection plates) or incubated for $2 \mathrm{~h}$ at room temperature (IgG2a detection plates). Pooled sera from non-sensitized and OVA-sensitized mice were also included in each assay and served as the negative and positive controls, respectively. After incubation, the plates were carefully washed with PBST buffer five times. The biotin-conjugated rat anti-mouse IgE monoclonal antibody (BD PharMignen) and biotin-conjugated rat anti-mouse $\operatorname{IgG}_{2 \mathrm{a}}$ monoclonal antibody (BD PharMignen) were diluted 1:2000 in blocking solution, respectively. Aliquots of $100 \mu \mathrm{l} /$ well diluted biotin-conjugated rat anti-mouse $\operatorname{IgE}$ and $\operatorname{IgG}_{2 \mathrm{a}}$ monoclonal antibody were respectively pipeted into the 96 microplate wells and incubated for $2 \mathrm{~h}$ and $1 \mathrm{~h}$ at room temperature. After incubation, the plates were carefully washed with PBST buffer six times. The avidin-conjugated alkaline phosphatase (Sigma) and avidin-conjugated horseradish peroxidase (Pierce) were diluted 1:2000 in blocking solution. Aliquots of $100 \mu \mathrm{l} /$ well diluted avidin-conjugated alkaline phosphatase (for IgE plates) and avidin-conjugated horseradish peroxidase (for $\operatorname{IgG}_{2 a}$ plates) were pipeted into the 96 microplate wells and incubated for $2 \mathrm{~h}$ and $1 \mathrm{~h}$, respectively, at room temperature. After incubation, the plates were carefully washed with PBST buffer eight times. Aliquots of $100 \mu \mathrm{l} /$ well $p$-nitrophenyl phosphate (pNPP, Sigma), the substrate of alkaline phosphatase, and 2,2'-azino-bis-(3-ethylbenzthiazoline-6sulfonic acid (ABTS, Sigma), the substrate of horseradish peroxidase, were then pipeted into the 96 microplate wells, respectively. After moderate incubation to develop the color, the plates were read on a plate reader (ELISA reader, ASYS Hitech GmbH, Austria) at $415 \mathrm{~nm}$ for IgE detection and $405 \mathrm{~nm}$ for $\operatorname{IgG}_{2 a}$ detection, respectively. Absorbency $(A)$ was measured at $405 \mathrm{~nm}$ with the ELISA reader and optical densities were converted into arbitrary ELISA units (EU) (Schmid-Grendelmeier et al., 2005). The ELISA unit $=\left(A_{\text {sample }}-A_{\text {blank }}\right) /\left(A_{\text {positive }}-A_{\text {blank }}\right)$.

\subsection{Statistical analysis}

Data are expressed as mean $\pm \mathrm{SE}$ and statistically analyzed using ANOVA followed, if justified by the statistical probability $(P<0.05)$, by Dunnett's test of parametric type. Differences between the dietary control and other groups were considered statistically significant if $P<0.05$.

\section{Results}

\subsection{Effects of G. tsugae supplementation on total cell numbers of peritoneal macrophages and splenocytes from OVA-sensitized and-challenged mice}

Sensitization and challenge with OVA significantly $(P<0.05)$ increased an influx of total leukocytes (increase from $2.76 \pm 0.34 \times 10^{6}$ to $23.97 \pm 4.80 \times 10^{6}$ cells/mouse) 
Table 1

Effects of $G$. tsugae supplementation on the number of spleen and peritoneal cells from ovalbumin-sensitized and -challenged female BALB/ c mice through 5 weeks feeding

\begin{tabular}{lll}
\hline & \multicolumn{2}{l}{ Total cell numbers } \\
\cline { 2 - 3 } & $\begin{array}{l}\text { Splenocytes } \\
\left(\times 10^{7} \text { cells/mouse }\right)\end{array}$ & $\begin{array}{l}\text { Peritoneal cells } \\
\left(\times 10^{6} \text { cells/mouse }\right)\end{array}$ \\
\hline Sensitized control (SC) & $4.35 \pm 0.44$ & $2.76 \pm 0.34^{*}$ \\
Dietary control (DC) & $6.66 \pm 0.86$ & $23.97 \pm 4.80$ \\
YK01-L & $5.72 \pm 0.75$ & $24.34 \pm 6.10$ \\
YK01-H & $6.46 \pm 1.64$ & $26.88 \pm 5.12$ \\
YK07-L & $5.92 \pm 1.65$ & $28.88 \pm 5.11$ \\
YK07-H & $5.10 \pm 1.10$ & $41.50 \pm 7.80$ \\
\hline
\end{tabular}

Each value represents a mean $\pm \mathrm{SE}(n=14)$.

* means $P<0.05$ vs. dietary control (DC) group in the same column.

into the peritoneal cavity of OVA-sensitized and -challenged mice (Table 1). However, G. tsugae, YK01-L, YK01-H, YK07-L, and YK07-H, supplementation did not significantly affect the total leukocyte influx into the peritoneal cavity of OVA-challenged mice. Sensitization and challenge with OVA did not significantly affect lymphocyte infiltration into the spleens. G. tsugae supplementation could not significantly affect total cell numbers in the mice' spleens.

\subsection{Effects of $G$. tsugae supplementation on the levels of Th1/Th2 cytokines in splenocyte cultures from \\ $O V A$-sensitized and-challenged mice}

To evaluate the effects of $G$. tsugae supplementation on the secretion of Th1/Th2 cytokines in the spleens, the concentration of IL-2 (Th1 cytokine), and IL-4 (Th2 cytokine) in the splenocyte cultures were measured (Table 2). The splenocytes were cultured with specific antigens (OVAstimulated) or without (spontaneous). Table 2 shows that sensitization and challenge with OVA significantly decreased the spontaneous production of IL-2 cytokines in splenocyte cultures. Sensitization and challenge with OVA did not significantly affect the OVA-stimulated IL-2 level. G. tsugae supplementation diets, YK01-L, YK01-H, YK07-L, and YK07-H, significantly increased the spontaneous production of IL-2 cytokine in splenocyte cultures. The YK07-L G. tsugae supplementation diet significantly increased the OVA-stimulated IL-2 level compared to the DC group, however the YK01-L, YK01-H, and YK07-H G. tsugae supplementation diets did not significantly increase the OVA-stimulated IL-2 levels in splenocyte cultures.

Sensitization and challenge with OVA significantly increased both the spontaneous and OVA-stimulated IL4 levels in splenocyte cultures. The YK01-L and YK07-H G. tsugae supplementation diets significantly decreased the spontaneous production of IL-4 cytokine in splenocyte cultures, however the YK01-H and YK07-L G. tsugae supplementation diets did not significantly affect the spontaneous production of IL-4 cytokine. The YK07-L G. tsugae supplementation diet significantly increased the OVA-stimulated IL-4 level, however the YK01-H, and YK07-H G. tsugae supplementation diets did not significantly increase the OVA-stimulated IL-4 levels in splenocyte cultures.

\subsection{Effects of $G$. tsugae supplementation on the levels of pro-inflammatory cytokines in peritoneal macrophage cultures from OVA-sensitized and-challenged mice}

To investigate the effects of $G$. tsugae supplementation on the peritoneal macrophages in vivo, the pro-inflammatory cytokines IL-1 $\beta$ and IL- 6 in peritoneal macrophage cultures from OVA-challenged mice through five weeks feeding were determined (Table 3). The peritoneal macrophages were cultured in the condition without (spontaneous) or with stimuli (LPS/IFN- $\gamma$-stimulated). The spontaneous cytokine levels represent the expression of peritoneal macrophages in the absence of stimulus. The LPS/IFN- $\gamma$-stimulated cytokine levels represent the expression of macrophages in the presence of foreign antigens (LPS). The macrophages were activated by IFN- $\gamma$. Table 3 shows that sensitization and challenge with OVA significantly decreased both spontaneous and LPS/IFN- $\gamma$-stimulated IL-1 $\beta$ and IL-6 levels in peritoneal macrophage cultures. The YK07-H G. tsugae supplementation diet significantly increased the spontaneous and LPS/IFN- $\gamma$ stimulated IL-1 $\beta$ levels. Although YK01-L, YK01-H, and YK07-L did not significantly increase the spontaneous and LPS/IFN- $\gamma$-stimulated IL-1 $\beta$ levels, these $G$. tsugae supplementation diets at least partially reversed the

Table 2

G. tsugae supplementation effects on IL-2 and IL-4 cytokine levels secreted by splenocytes from ovalbumin-sensitized and -challenged female BALB/c mice through five weeks feeding

\begin{tabular}{|c|c|c|c|c|}
\hline \multirow[t]{2}{*}{ Groups } & \multicolumn{2}{|c|}{ IL-2 (pg/10 6 cells $)$} & \multicolumn{2}{|c|}{ IL-4 (pg/10 6 cells $)$} \\
\hline & Spontaneous & OVA-stimulated & Spontaneous & OVA-stimulated \\
\hline Non-sensitized control (SC) & $0.586 \pm 0.027^{*}$ & $0.637 \pm 0.032$ & $4.135 \pm 0.191^{*}$ & $4.375 \pm 0.209^{*}$ \\
\hline Dietary control (DC) & $0.402 \pm 0.025$ & $0.776 \pm 0.029$ & $4.889 \pm 0.230$ & $6.642 \pm 0.501$ \\
\hline YK01-L & $0.589 \pm 0.032^{*}$ & $0.869 \pm 0.040$ & $4.049 \pm 0.263^{*}$ & $6.115 \pm 0.323$ \\
\hline YK01-H & $0.563 \pm 0.019^{*}$ & $0.916 \pm 0.049$ & $4.580 \pm 0.160$ & $6.900 \pm 0.341$ \\
\hline YK07-L & $0.911 \pm 0.054^{*}$ & $1.129 \pm 0.053^{*}$ & $5.304 \pm 0.121$ & $8.575 \pm 0.354^{*}$ \\
\hline YK07-H & $0.558 \pm 0.065^{*}$ & $0.951 \pm 0.071$ & $3.467 \pm 0.116^{*}$ & $7.047 \pm 0.566$ \\
\hline
\end{tabular}

Each value represents a mean $\pm \mathrm{SE}(n=14)$.

* means $P<0.05$ vs. dietary control (DC) group in the same column. The concentration of OVA was $25 \mu \mathrm{g} / \mathrm{ml}$. 
Table 3

G. tsugae supplementation effects on IL-1 $\beta$ and IL-6 cytokine levels secreted by peritoneal macrophages from ovalbumin-sensitized and -challenged female $\mathrm{BALB} / \mathrm{c}$ mice through 5 weeks feeding

\begin{tabular}{|c|c|c|c|c|}
\hline \multirow[t]{2}{*}{ Groups } & \multicolumn{2}{|c|}{ IL- $1 \beta\left(\mathrm{pg} / 10^{6}\right.$ cells $)$} & \multicolumn{2}{|c|}{ IL-6 (ng/10 cells $)$} \\
\hline & Spontaneous & LPS/IFN- $\gamma$-stimulated & Spontaneous & LPS/IFN- $\gamma$-stimulated \\
\hline Non-sensitized control (SC) & $43.19 \pm 5.74^{*}$ & $189.64 \pm 10.44^{*}$ & $4.52 \pm 0.16^{*}$ & $20.22 \pm 2.61^{*}$ \\
\hline Dietary control (DC) & $13.29 \pm 2.78$ & $55.12 \pm 8.17$ & $3.98 \pm 0.02$ & $6.04 \pm 0.52$ \\
\hline YK01-L & $8.12 \pm 1.91$ & $60.24 \pm 7.56$ & $5.56 \pm 0.01^{*}$ & $7.16 \pm 0.274$ \\
\hline YK01-H & $15.54 \pm 2.16$ & $68.47 \pm 2.89$ & $5.56 \pm 0.02^{*}$ & $7.06 \pm 0.15$ \\
\hline YK07-L & $19.20 \pm 2.94$ & $61.19 \pm 7.23$ & $4.99 \pm 0.01^{*}$ & $6.16 \pm 0.17$ \\
\hline YK07-H & $38.92 \pm 2.72^{*}$ & $83.95 \pm 3.61^{*}$ & $5.06 \pm 0.07^{*}$ & $6.75 \pm 0.20$ \\
\hline
\end{tabular}

Each value represents a mean $\pm \mathrm{SE}(n=14)$.

${ }^{*}$ means $P<0.05$ vs. dietary control (DC) group in the same column. The concentrations of LPS and IFN- $\gamma$ were $10 \mu \mathrm{g} / \mathrm{ml}$ and $50 \mathrm{units} / \mathrm{ml}$, respectively.

suppression of IL-1 $\beta$ caused by immune challenge. $G$. tsugae supplementation, YK01-L, YK01-H, YK07-L, and YK07-H, significantly increased spontaneous IL-6 levels, however $G$. tsugae supplementation slightly increased the LPS/IFN- $\gamma$-stimulated IL-1 $\beta$ levels.

\subsection{Effects of $G$. tsugae supplementation on inflammatory mediator (nitric oxide) levels in peritoneal macrophage cultures from OVA-sensitized and-challenged mice}

To further investigate the G. tsugae supplementation effects on the peritoneal macrophages in vivo, the inflammatory mediator nitric oxide (NO) in peritoneal macrophage cultures from OVA-challenged mice through five weeks feeding were determined (Table 4). Sensitization and challenge with OVA significantly decreased the spontaneous and LPS/IFN- $\gamma$-stimulated NO levels in peritoneal macrophage cultures, however G. tsugae supplementation diets did not significantly affect NO secretion levels.

\subsection{Effects of $G$. tsugae supplementation on levels of $O V A$-specific $\operatorname{Ig} E$, and $\operatorname{Ig} G_{2 a}$ antibody in serum from OVA-sensitized and-challenged mice}

To determine G. tsugae supplementation effects on antigen-specific antibodies in vivo, the OVA-specific IgE (Th2type immunoglobulin), and $\mathrm{IgG}_{2 \mathrm{a}}$ (Th1-type immunoglob-

Table 4

G. tsugae supplementation effects on nitric oxide level secreted by peritoneal macrophages from ovalbumin-sensitized and -challenged female BALB/c mice through 5 weeks feeding

\begin{tabular}{llc}
\hline Groups & \multicolumn{2}{l}{ Nitric oxide $(\mathrm{NO})\left(n\right.$ mol $/ 10^{6}$ cells $)$} \\
\cline { 2 - 3 } & Spontaneous & LPS/IFN- $\gamma$-stimulated \\
\hline Non-sensitized control (SC) & $0.790 \pm 0.106^{*}$ & $33.872 \pm 3.940^{*}$ \\
Dietary control (DC) & $0.480 \pm 0.028$ & $0.704 \pm 0.066$ \\
YK01-L & $0.461 \pm 0.056$ & $1.494 \pm 0.265$ \\
YK01-H & $0.373 \pm 0.039$ & $0.982 \pm 0.107$ \\
YK07-L & $0.458 \pm 0.066$ & $1.061 \pm 0.094$ \\
YK07-H & $0.394 \pm 0.034$ & $0.968 \pm 0.107$ \\
\hline
\end{tabular}

Each value represents a mean $\pm \mathrm{SE}(n=14)$.

* means $P<0.05$ vs. dietary control (DC) group in the same column. The concentrations of LPS and IFN- $\gamma$ were $10 \mu \mathrm{g} / \mathrm{ml}$ and 50 units $/ \mathrm{ml}$, respectively.
Table 5

G. tsugae supplementation effects on levels of serum OVA-specific antibodies from ovalbumin-sensitized female $\mathrm{BALB} / \mathrm{c}$ mice through 3 weeks feeding

\begin{tabular}{lll}
\hline & \multicolumn{2}{l}{ OVA-specific antibody (ELISA unit) } \\
\cline { 2 - 3 } & $\mathrm{IgE}$ & $\mathrm{IgG}_{2 \mathrm{a}}$ \\
\hline Non-sensitized control (SC) & $0.030 \pm 0.007^{*}$ & $0.038 \pm 0.012^{*}$ \\
Dietary control (DC) & $0.300 \pm 0.016$ & $0.321 \pm 0.092$ \\
YK01-L & $0.220 \pm 0.029$ & $0.287 \pm 0.068$ \\
YK01-H & $0.312 \pm 0.057$ & $0.255 \pm 0.052$ \\
YK07-L & $0.273 \pm 0.046$ & $0.249 \pm 0.083$ \\
YK07-H & $0.273 \pm 0.046$ & $0.315 \pm 0.072$ \\
\hline
\end{tabular}

Each value represents a mean $\pm \mathrm{SE}(n=14)$.

* means $P<0.05$ vs. dietary control (DC) group in the same column.

ulin) antibody levels in serum from OVA-sensitized and -challenged mice through 3 and 5 weeks feeding were examined, respectively (Tables 5 and 6). Sensitization (Table 5) and challenge (Table 6) with OVA significantly increased the serum OVA-specific IgE, and $\mathrm{IgG}_{2 \mathrm{a}}$ levels. Significant antibody responses indicated that OVA-specific immune responses were induced by OVA antigens in the OVA-sensitized and -challenged mouse models during either the 3 or 5 weeks experimental periods. However, G. tsugae supplementation did not significantly affect both OVA-specific IgE (Th2-type immunoglobulin) and $\operatorname{IgG}_{2 \mathrm{a}}$ (Th1-type immunoglobulin) antibodies in serum either through 3 or 5 weeks consecutive feeding.

Table 6

G. tsugae supplementation effects on levels of serum OVA-specific antibodies from ovalbumin-sensitized and -challenged female BALB/c mice through 5 weeks feeding

\begin{tabular}{lll}
\hline & \multicolumn{2}{l}{ OVA-specific antibody (ELISA unit) } \\
\cline { 2 - 3 } & $\operatorname{IgE}$ & $\operatorname{IgG}_{2 \mathrm{a}}$ \\
\hline Non-sensitized control (SC) & $0.002 \pm 0.009^{*}$ & $0.033 \pm 0.002^{*}$ \\
Dietary control (DC) & $0.330 \pm 0.059$ & $0.541 \pm 0.142$ \\
YK01-L & $0.503 \pm 0.086$ & $0.420 \pm 0.076$ \\
YK01-H & $0.351 \pm 0.038$ & $0.407 \pm 0.057$ \\
YK07-L & $0.266 \pm 0.042$ & $0.487 \pm 0.110$ \\
YK07-H & $0.489 \pm 0.142$ & $0.666 \pm 0.124$
\end{tabular}

Each value represents a mean $\pm \mathrm{SE}(n=14)$.

* means $P<0.05$ vs. dietary control (DC) group in the same column. 


\section{Discussion}

In this study, we report on the immuno-modulatory effects of G. tsugae supplementation diets on Th1/Th2 immune responses and peritoneal macrophages in an OVA-induced allergic disease mouse model. In this established allergic disease animal model, sensitization and challenge with OVA significantly $(P<0.05)$ decreased the IL2/ IL-4 (Th1/Th2) ratio in the spontaneous and OVA-stimulated splenocyte cultures (decrease from $147.2 \pm 28.0 \mathrm{pg} /$ $\mathrm{ng}$ to $88.1 \pm 23.9 \mathrm{pg} / \mathrm{ng}$ and from $155.2 \pm 40.6 \mathrm{pg} / \mathrm{ng}$ to $121.7 \pm 35.5 \mathrm{pg} / \mathrm{ng}$, respectively) from OVA-sensitized and -challenged mice (Fig. 1). The spontaneous Th1/Th2 balance might reflect the natural immune responses in this animal model. The OVA-sensitized and -challenged mice exhibited a Th2-skewed pattern in the spleen in vivo. However, G. tsugae supplementation diets significantly increased the IL2/IL-4 (Th1/Th2) ratios in the spontaneous splenocyte cultures (Fig. 1) compared to the dietary control (DC) group. Although G. tsugae supplementation merely slightly increased the IL2/IL-4 (Th1/Th2) ratios in the OVA-stimulated splenocyte cultures (Fig. 1), G. tsugae supplementation reversed an established Th2-skewed pattern to the Th1-skewed pattern of spleen immune responses in vivo. A Th2-skewed pattern in vivo might play a triggering role in the activation of the allergic inflammation (Maggi, 1998). These results indicate that G. tsugae supplementation diets, YK01 and YK07, modulated Th1/Th2 immune responses and enhanced the Th1 cytokine production in an OVA sensitization and challenge mouse model.
There has been increasing evidence to support therapeutic application of traditional medicines or health foods in allergic diseases by modulating the Th1/Th2 balance via different immuno-modulatory mechanisms (Li et al., 2000; Cross et al., 2001; Kato et al., 2003; Ko et al., 2004; Edwan et al., 2005). In this study, G. tsugae, was also introduced to modulate the humoral immune responses in vivo. However, G. tsugae supplementation did not significantly affect both OVA-specific IgE (Th2-type immunoglobulin) and $\operatorname{IgG}_{2 a}$ (Th1-type immunoglobulin) antibodies in serum (Tables 5 and 6). The overall effects of G. tsugae supplementation on serum antibody levels and Th1/Th2 balance remain to be further clarified. However, the supplementation diet still could not fully reverse the Th2-skewed responses to the level of Th1-slewed responses.

Our results showed that the dietary supplementation of G. tsugae decreased the spontaneous IL-4, but increased the IL-2 production, indicating the modulation of Th1/ Th2 balance via G. tsugae supplementation in vivo. However, the supplementation diet increased both IL-2 and IL-4 production under the OVA stimulation, enhancing the immune responses by $G$. tsugae supplementation. The enhancement of immune responses might also increase the inflammation potential. G. tsugae supplementation in vivo exhibited differential effects on the Th1/Th2 balance and inflammation potential in vitro, depending on different culture conditions. Splenocyte cultures treated with specific antigen OVA in vitro were to imitate the presence of foreign antigens, such as allergen, bacteria, and virus, that had been encountered by immune cells in vivo. However, we

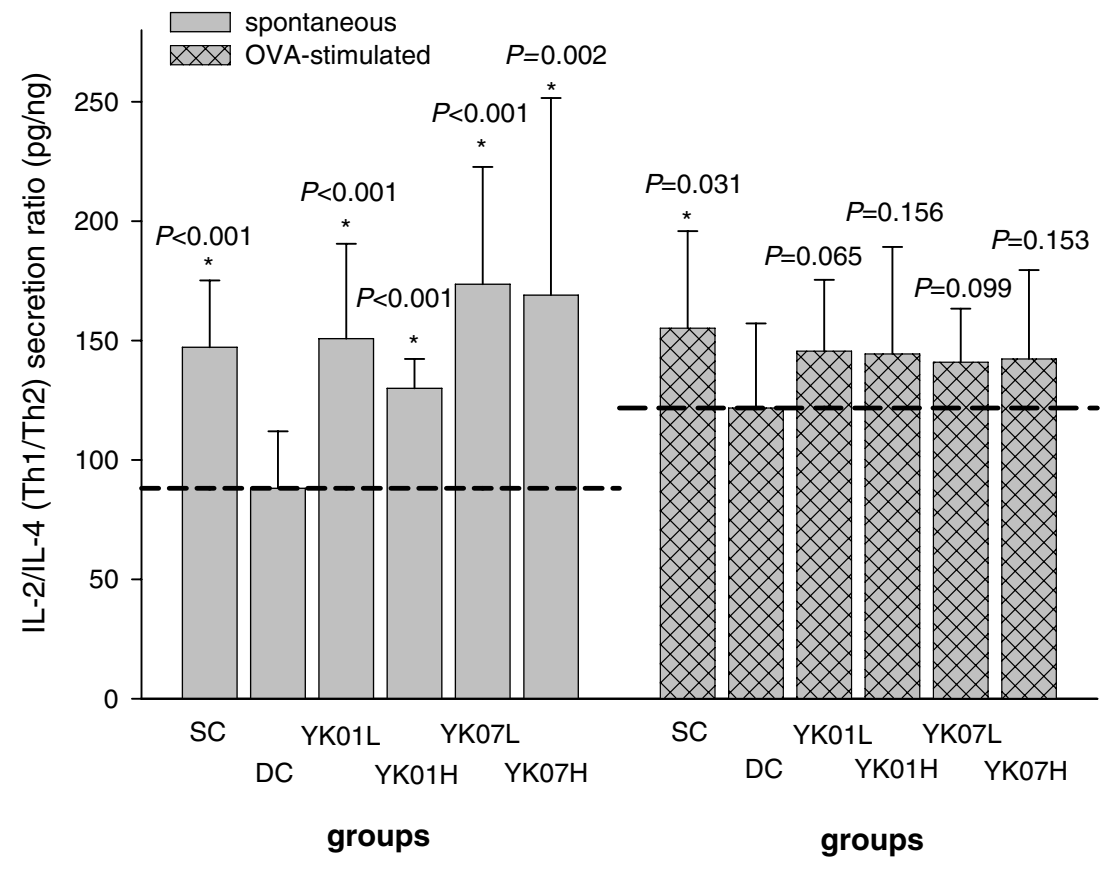

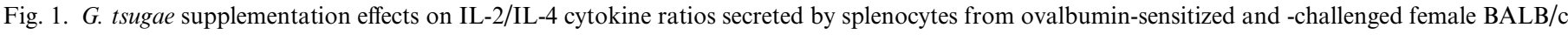

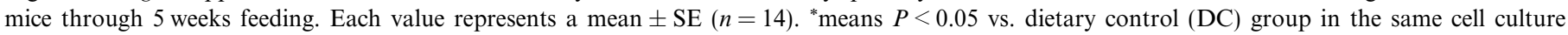
treatment. 
presumed that the addition of the specific antigen to the splenocyte cultures might increase the antigen (or disease) stress and change the immune responses in vitro. According to the results in vitro, we suggest that G. tsugae supplementation in the presence of antigen (or disease) stress might further enhance the immune responses, such as increases in Th1 and Th2 cytokines, and the risk of inflammation might be increased. A traditional Chinese and Japanese medicine, Bu-Zhong-yi-qi-tang (Japanese name: Hochuekki-to, HOT), also exerts a dichotomous effect on allergic asthmatic inflammation in mice (Ishimitsu et al., 2001). HOT administrated in the eliciting phase (late asthmatic response), well after the Th2 responses have developed, aggravates the allergic inflammation after OVA inhalation. HOT is suggested to be applicable for prophylactic use to prevent allergy responses but must be used carefully for patients with apparent allergic inflammation. In this study the results further suggest that $G$. tsugae supplementation is applicable for the modulation of Th1/Th2 balance daily for allergic patients but must be used carefully for patients with apparent antigen or disease stress.

Macrophages are involved in non-specific and specific immune responses in vivo. In this study, sensitization and challenge with OVA decreased the pro-inflammatory cytokine IL- $1 \beta$ and IL- 6 production, and the inflammatory mediator nitric oxide in cultured peritoneal macrophages from OVA-sensitized and -challenged mice (Tables 3 and 4). These results suggest that immune responses of macrophages are inhibited by the repeated processes of sensitization and challenge with OVA. However, most of the $G$. tsugae supplementation diets enhanced the pro-inflammatory cytokine IL-1 $\beta$ and IL- 6 production in cultured peritoneal macrophages (Table 3) but did not significantly change the inflammatory mediator levels of nitric oxide (Table 4). The increase in pro-inflammatory cytokines might increase the possibility of inflammation in vivo. However, G. tsugae supplementation did not significantly change the inflammatory mediator nitric oxide levels. These results suggest that $G$. tsugae supplementation might increase peritoneal macrophage responses but not induce severe inflammation in an allergic animal model.

Bioactive constituents of $G$. tsugae have been constantly unraveled (Peng and Zhang, 2003; Su et al., 2001). It has been reported that lipopeptide and saponin adjuvants modulate the Th1/Th2 bias in orally immunized mice (Huber et al., 2002). Recently, Takano et al. (2005) found that proteoglycans (about $91 \%$ polysaccharide and $7 \%$ protein) from Paecilomyces tenuipes (Peck) Samson and Paecilomyces cicadae (Miquel) Samson liquid culture filtrates showed a strong immunopotent activity. The proteoglycan-rich fraction regulates Th1 and Th2 cytokine response in murine Peyer's patch cells in vitro and ex vivo (Takano et al., 2005). We assumed that polysaccharides and saponins might be the immuno-modulatory components in G. tsugae. However, the immuno-active constitutes and pharmaceutical effects of G. tsugae on the Th1/Th2 balance remain to be further elucidated.
The magnitude of the immune response generally depends on the antigen (or stimulant) dose administered. However, very low or very high doses of antigen (or stimulant) may induce specific unresponsive states. Thus, acquired low-zone or high-zone tolerance, respectively, are known under some conditions. There is no dose-dependency in this study between low and high supplementation diet doses under some conditions. We assumed that high dose supplementation with $G$. tsugae might result in highzone immune response tolerance, however low dose supplementation of $G$. tsugae might cause low-zone immune response tolerance under some in vivo or in vitro conditions. As G. tsugae product is consumed daily by particular people, we suggest low dose and long term supplementation with $G$. tsugae might be a suitable way.

The main purpose of this study was to evaluate the health function of health foods and provide some scientific evidence. Generally, health foods are consumed freely daily by healthy people or people with mild diseases such as allergic disorders. The G. tsuga products used in this study are available in commercial health food products authorized by the government of Taiwan. Many people have consumed these products daily for many years in Taiwan. Some individuals that had commonly suffered from allergies in the past feel alleviatory effects from their allergic syndromes after dietary supplementation with $G$. tsuga products. However, a scientific human study on $G$. tsuga products has not yet been performed. This animal study of $G$. tsugae provides preliminary data concerning the immuno-modulation of Th1/Th2 and macrophage responses in an allergic murine model. We did not determine how much of the active ingredients ever reached the bloodstream or the target cells. To develop a drug from G. tsugae, more studies should be performed in the future.

In summary, G. tsugae supplementation in vivo modulated the Th1/Th2 balance and enhanced macrophage immune responses, however the supplementation diet could not fully reverse the Th2-skewed responses to the level of Th1-skewed responses.

\section{Acknowledgement}

This study was kindly supported by grants from YungKien Industry Corp, Double Crane Group, Taiwan, Republic of China (ROC).

\section{References}

Chen, H.-S., Tsai, Y.-F., Lin, S., Lin, C.-C., Khoo, K.-H., Lin, C.-H., Wong, C.-H., 2004. Studies on the immuno-modulating and antitumor activities of Ganoderma lucidum (Reishi) polysaccharides. Bioorganic and Medicinal Chemistry 12, 5595-5601.

Chien, C.M., Cheng, J.-L., Chang, W.-T., Tien, M.-H., Tsao, C.-M., Chang, Y.-H., Chang, H.-Y., Hsieh, J.-F., Wong, C.-H., Chen, S.-T., 2004. Polysaccharides of Ganoderma lucidum alter cell immunophenotypic expression and enhance $\mathrm{CD}_{5} 6^{+}$NK-cell cytotoxicity in cord blood. Bioorganic and Medicinal Chemistry 12, 56035609 . 
Cross, M.L., Stevenson, L.M., Gill, H.S., 2001. Anti-allergy properties of fermented foods: an important immuno-regulatory mechanism of lactic acid bacteria? International Immuno-pharmacology 1, 891-901.

Edwan, J.H., Talmadge, J.E., Agrawal, D.K., 2005. Treatment with Flt3 ligand plasmid reverses allergic airway inflammation in ovalbuminsensitized and -challenged mice. International Immuno-pharmacology $5,345-357$.

Huber, M., Baier, W., Bessler, W.G., Heinevetter, L., 2002. Modulation of Th1/Th2 bias by lipopeptide and saponin adjuvants in orally immunized mice. Immunobiology 205, 61-73.

Ishimitsu, R., Nishimura, H., Kawauchi, H., Kawakita, T., Yoshikai, Y., 2001. Dichotomous effect of a traditional Japanese medicine, Buzhong-yi-qi-tang on allergic asthma in mice. International Immunopharmacology 1, 857-865.

Kato, Y., Negishi, T., Furusako, S., Mizuguchi, K., Mochizuki, H., 2003. An orally active Th1/Th2 balance modulator, M50367, suppresses Th2 differentiation of naïve Th cell in vitro. Cellular Immunology 224, 29 37.

Ko, E., Rho, S., Lee, E.-J., Seo, Y.-H., Cho, C., Lee, Y., Min, B.-I., Shin, M.-K., Hong, M.-C., Bae, H., 2004. Traditional Korean medicine (SCRT) modulate Th1/Th2 specific cytokine production in mice CD4+ T cell. Journal of Ethno-pharmacology 92, 121-128.

Lai, N.S., Lin, R.H., Lai, R.S., Kun, U.C., Leu, S.C., 2001. Prevention of autoantibody formation and prolonged survival in New Zealand Black/New Zealand White F1 mice with an ancient Chinese herb, Ganoderma tsugae. Lupus 10, 461-465.

Lin, J.-Y., Chen, M.-L., Chiang, B.-L., Lin, B.-F., 2006. Ganoderma tsugae supplementation alleviates bronchoalvelar inflammation in an airway sensitization and challenge mouse model. International Immuno-pharmacology 6, 241-251.

Li, X.-M., Huang, C.-K., Zhang, T.-F., Teper, A.A., Srivastava, K., Schofield, B.H., Sampson, H.A., 2000. The Chinese herbal medicine formula MSSN-002 suppresses allergic airway hyperreactivity and modulates Th1/Th2 responses in a murine model of allergic asthma. Journal of Allergy and Clinical Immunology 106, 660-668.

Maggi, E., 1998. The TH1/TH2 paradigm in allergy. Immunotechnology $3,233-244$.

Morokata, T., Ishikawa, J., Yamada, T., 1999. Differential susceptibility of $\mathrm{C} 57 \mathrm{BL} / 6$ and $\mathrm{DBA} / 2$ mice to ovalbumin-induced pulmonary eosinophilia regulated by $\mathrm{Th} 1 / \mathrm{Th} 2$-type cytokines. Immunology Letters $70,127-134$.

Nagai, T., Arai, Y., Emori, M., Nunome, S., Yabe, T., Takeda, T., Yamada, H., 2004. Anti-allergic activity of a Kampo (Japanese herbal) medicine"Sho-seiryyu-to (Xiao-Qing-Long-Tang)" on airway inflammation in a mouse model. International Immunopharmacology 4, $1353-1365$.

Ogawara, H., Handa, H., Yamazaki, T., Toda, T., Yoshida, K., Nishimoto, N., Al-ma'Quol, W.H.S., Kaneko, Y., Matsushima, T., Tsukamoto, N., Nojima, Y., Matsumoto, M., Sawamura, M., Mura- kami, H., . High Th1/Th2 ratio in patients with multiple myeloma. Leukemia Research 29, 135-140.

Peng, Y., Zhang, L., 2003. Characterization of a polysaccharide-protein complex from Ganoderma tsugae mycelium by size-exclusion chromatography combined with laser light scattering. Journal of Biochemical and Biophysical Methods 56, 243-252.

Peng, Y., Zhang, L., Zeng, F., Kennedy, J.F., 2005. Structure and antitumor activities of the water-soluble polysaccharides from Ganoderma tsugae mycelium. Carbohydrate Polymers 59, 385-392.

Peng, Y., Zhang, L., Zeng, F., Xu, Y., 2003. Structure and antitumor activity of extracellular polysaccharides from mycelium. Carbohydrate Polymers 54, 297-303.

Romagnani, S., 2000. The role of lymphocytes in allergic disease. Journal of Allergy and Clinical Immunology 105, 399-408.

Schmid-Grendelmeier, P., Fluckiger, S., Disch, R., Trautmann, A., Wuthrich, B., Blaser, K., Scheynius, A., Crameri, R., 2005. IgEmediated and $\mathrm{T}$ cell-mediated auto-immunity against manganese superoxide dismutase in atopic dermatitis. Journal of Allergy and Clinical Immunology 115, 1068-1075.

Su, C.H., Sun, C.S., Juan, S.W., Ho, H.O., Hu, C.H., Sheu, M.T., 1999. Development of fungal mycelia as skin substitutes: effects on wound healing and fibroblast. Biomaterials 20, 61-68.

Su, C.H., Yang, Y.Z., Ho, H.O., Hu, C.H., Sheu, M.T., 2001. Highperformance chromatographic analysis for the characterization of triterpenoids from Ganoderma. Journal of Chromatography Science 39, 93-100.

Takano, F., Yahagi, N., Yahagi, R., Takada, S., Yamaguchi, M., Shoda, S., Murase, T., Fushiya, S., Ohta, T., 2005. The liquid culture filtrates of Paecilomyces tenuipes (Peck) Samson (=Isaria japonica Yasuda) and Paecilomyces cicadae (Miquel) Samson (=Isaria sinclairii (Berk) Llond) regulate Th1 and Th2 cytokine response in murine Peyer's patch cells in vitro and ex vivo. International Immunopharmacology 5 , 903-916.

Wang, G., Zhang, J., Mizuno, T., Zhuang, C., Ito, H., Mayuzumi, H., Okamoto, H., Li, J., 1993. Antitumor active polysaccharides from the Chinese mushroom Songshan lingzhi, the fruiting body of Ganoderma tsugae. Bioscience, Biotechnology, and Biochemistry 57, 894-900.

Wang, Y.-Y., Khoo, K.-H., Chen, S.-T., Lin, C.-C., Wong, C.-H., Lin, C.H., 2002. Studies on the immuno-modulating and activities of Ganoderma lucidum (Reishi) polysaccharides: functional and protemic analyses of a fucose-containing glycoprotein fraction responsible for the activities. Bioorganic and Medicinal Chemistry 10, 1057-1062.

Won, S.J., Lin, M.T., Wu, W.L., 1992. Ganoderma tsugae mycelium enhances splenic natural killer cell activity and serum interferon production in mice. Japan Journal of Pharmacology 59, 171-176.

Wu, Y.W., Chen, K.D., Lin, W.C., 2004. Effects of Ganoderma tsugae on chronically carbon tetrachloride-intoxicated rats. American Journal of Chinese Medicine 32, 841-850. 